\title{
Investigating Job Stress among Professional Drivers
}

\author{
Farzaneh Rahimpour ${ }^{1}$, Lida Jarahi $^{2}$, Ehsan Rafeemanesh ${ }^{1}$, Atefeh Taghati ${ }^{3} \&$ Fatemeh Ahmadi $^{1}$ \\ ${ }^{1}$ Occupational Medicine Specialist, Assistant Professor of Occupational Medicine, Faculty of Medicine, \\ Mashhad University of Medical Sciences, Mashhad, Iran \\ ${ }^{2}$ Community Medicine Specialist, Associated Professor of Community Medicine, Addiction Research Center, \\ Faculty of Medicine, Mashhad University of Medical Sciences, Mashhad, Iran \\ ${ }^{3}$ Occupational Medicine Specialist, Iran \\ Correspondence: Fatemeh Ahmadi, Faculty of Medicine, University Campus, Azadi Roundabout, Mashhad, Iran. \\ Tel: +098-51-3800-2176. E-mail: ahmadif@mums.ac.ir
}

Received: December 7, 2019

Accepted: January 18, 2020

Online Published: March 30, 2020

doi:10.5539/jmbr.v10n1p29

URL: https://doi.org/10.5539/jmbr.v10n1p29

\begin{abstract}
Purpose: Psychological stress is one of the main occupational hazards. The aim of this study was evaluating psychological stress in terms of role stress and its domains in professional drivers.

Methods: This cross-sectional study was conducted on 300 heavy vehicle drivers and 330 light vehicle drivers. Data were collected using interview and Osipow job stress questionnaire. T-test 'ANOVA 'chi-square test and linear regression were used in analyzing the data.

Results: $33.2 \%$ of the participants had mild to moderate stress. Independent psychological stress predictors were vehicle type, shift work, job satisfaction, and income. Stress scores were higher in work overload, role conflict, responsibility, and work environment in heavy vehicle drivers than light vehicle drivers $(p<0.001)$, while this difference was not significant in terms of role insufficiency and ambiguity.

Conclusion: Nearly one-third of the drivers had mild to moderate stress level. Overall stress level was higher in heavy vehicle drivers than light vehicle drivers. The highest score in stress domains in all drivers attributed to the role insufficiency.
\end{abstract}

Keywords: driver, job, psychological stress

\section{Introduction}

Undoubtedly, stress is an integral part of today's life. On the basis of related literature, it is one of the main occupational hazards with numerous adverse effects on individual's health.

According to definition of the National Institute of Occupational Safety and Health (NIOSH), job stress occurs when there is no congruence between individuals' abilities and needs with their job demands (Hoel, Sparks, \& Cooper, n. d.). Job stress has been investigated by many reseracgers (Haider et al., 2018; Hannani et al., 2018) and it not only imposes direct costs on individuals due to physical and emotional diseases and disrupts individual performance (LaDou \& Harrison, 2014), but it also wastes millions of dollars of organizational costs via decreasing productivity and increasing absenteeism, accidents and insurance indemnities (Varmazyar, Mortazavi, Hajizadeh, \& Arghami, 2013). Ironically, stress costs account for 1 to $3.5 \%$ of Gross Domestic Product (GDP) (Tangri, 2003). The cost of stress-related issues reaches 20 billion euros a year in the EU (KIZILOĞLU, 2018).

Numerous variables affect individuals' vulnerability to job stress; however, in order to manage this problem there is a need for higher emphasis on stressors of workplaces than individual susceptibility. Stressors of workplaces are mainly classified into the following five categories: 1- Organizational (such as organizational changes and communication problems), 2- career development (such as lack of promotion opportunity), 3- role of the individual (e.g. role conflict and role ambiguity), 4- job task (such as the level of responsibility and decision-making latitude), and 5-Work environment (such as physical and chemical exposures). (LaDou \& Harrison, 2007)

Obviously, each job has its own stress characteristics. According to recent research, driving is among the stressful jobs. Driving requires skill, high concentration and accuracy, careful judgment and confidence in decision-making; therefore, increasing in drivers' stressors will end in accidents (Aminian, 2005). Some factors, 
which may cause job stress in driving, are as follows: long working hours; irregular work schedules; even and repetitive work; inappropriate physical conditions; lack of job support; and familial and social constraints. (Aminian, 2005; Siedlecka, 2006)

Job stress increases driver's mental and cognitive fatigue and leads to impaired job quality. According to Simon and Corbett's theory, stress and anxiety do not allow drivers to follow traffic laws and this increases the incidence of fatal accidents and economical loss. (Vrijkotte, Van Doornen, \& De Geus, 1999)

Considering the importance of the issue and since there are a few studies on different stress domains in professional drivers, and given different results in various studies, we decided to evaluate job stress in term of role stress and its domains in heavy vehicle and light vehicle drivers.

\section{Method}

The present study was a cross-sectional study conducted on professional drivers who were referred to an occupational medicine center for periodic examinations. Simple random sampling was used in this study. The required sample size was 627 based on the sample size formula in correlation studies:

$$
\begin{gathered}
\mathrm{z}_{1-\sigma_{/ 2}}=1.96 \\
\mathrm{z}_{1-[}=1.28 \\
\mathrm{r}=0.3) \\
\mathrm{n}=\left[\frac{1.96+1.28}{0.13}\right]^{2}+3=627
\end{gathered}
$$

The inclusion criteria were as follows: at least one year of work experience in professional driving and willingness to participate in the study. The exclusion criteria included a diagnosed anxiety disorder or history of consuming psychiatric drugs before initiating professional driving. Based on the inclusion criteria, 658 light and heavy vehicles drivers were selected to participate in the study. After considering the exclusion criteria, a total of 630 subjects were included in the study. 300 subjects were heavy vehicles drivers (bus, chemical tankers, trailer, truck, dump truck, light truck and other heavy vehicles) and 330 subjects were light vehicle drivers (taxi driver, agency driver, school service and company drivers). A two-part questionnaire was used in this study. The first part of the questionnaire included questions about demographic and occupational data of the subjects (age, education, marital status, smoking, regular exercise, type of vehicle, shift work pattern, monthly income level, rest duration (in hour), and job satisfaction). The second part covered Osipow job stress questionnaire (Osipow \& Spokan, 1998). This 60-item questionnaire evaluated the individuals' roles in six domains including work overload, role ambiguity, role insufficiency, role conflict, responsibility and work environment. Each sub-group had 10 questions. Responses were based on five-point Likert scale and each one was scored from 1 to 5 . Summing the scores, we put the individuals' total stress into one of the following four categories according to the questionnaire guide: mild stress (scores of 60-119), mild to moderate stress (171-120), moderate to severe stress (180-239), and severe stress (240-300). Validity and reliability of the questionnaire had been already investigated in Iran and the Cronbach's alpha coefficient was 83\% (Sharifian, Aminian, Kiani, Baruni, \& Amiri, 2005). It should be noted that the applied questionnaire of this study was completed by the participants under the supervision of a trained occupational hygiene expert.

Drivers were categorized into 3 groups according to their working shift pattern: 1) day-workers whose working hour was between 6 am to $6 \mathrm{pm}, 2$ ) night-workers whose working hour was between $6 \mathrm{pm}$ to 6 am and 3) drivers with varied working shift pattern.

In this study monthly income was defined in 3 groups: less than $188 \$, 188$ to $375 \$$ and more than $375 \$$.

Finally, collected data was statistically analyzed by SPSS-20 software. T-test, ANOVA, chi-square test and regression analysis were used to analyze data. Significance level was considered less than $5 \%(P-v a l u e<0.05)$ in all calculations. 


\section{Results}

The present study evaluated 630 professional drivers including 300 heavy vehicles drivers (bus, trailer, chemical tankers, truck, light truck, dump truck and other heavy vehicles) and 330 light vehicle drivers (taxi driver, agency driver, school service and company drivers). All of the participants were male. 610 subjects $(96.8 \%)$ were married. 600 subjects $(95.3 \%)$ had high school diploma and lower degrees. 370 subjects $(58.7 \%)$ had monthly income of less than $375 \$$. In terms of shift work, 259 subjects $(41.1 \%)$ were day-shift workers and 23 subjects (3.6\%) were night-shift workers, and 347 subjects $(3.55 \%)$ had varied shifts. 357 subjects $(56.6 \%)$ were smokers.

The mean age in heavy and light vehicle drivers was $44.33 \pm 6.6$ and $37.5 \pm 5.5$ years, respectively. According to the analysis, majority of the heavy vehicle drivers were older than or equal to 40 years of age, while only $37.9 \%$ of light vehicle drivers were in this age category $(\mathrm{P}<0.001$.) There were significant statistical differences between two groups of drivers in terms of monthly income, cigarette smoking, and type of shift work, so that monthly income and smoking were higher in heavy vehicle drivers, and $82.3 \%$ of heavy vehicle drivers had varied working hours, whereas most of the light vehicle drivers $(68.5 \%)$ were day-workers $(\mathrm{P}<0.001)$.

According to the study on job stress level in all drivers, most of the subjects (33.2\%) had mild to moderate stress level. Frequency distribution of job stress level in two groups of drivers is shown in Figure 1.

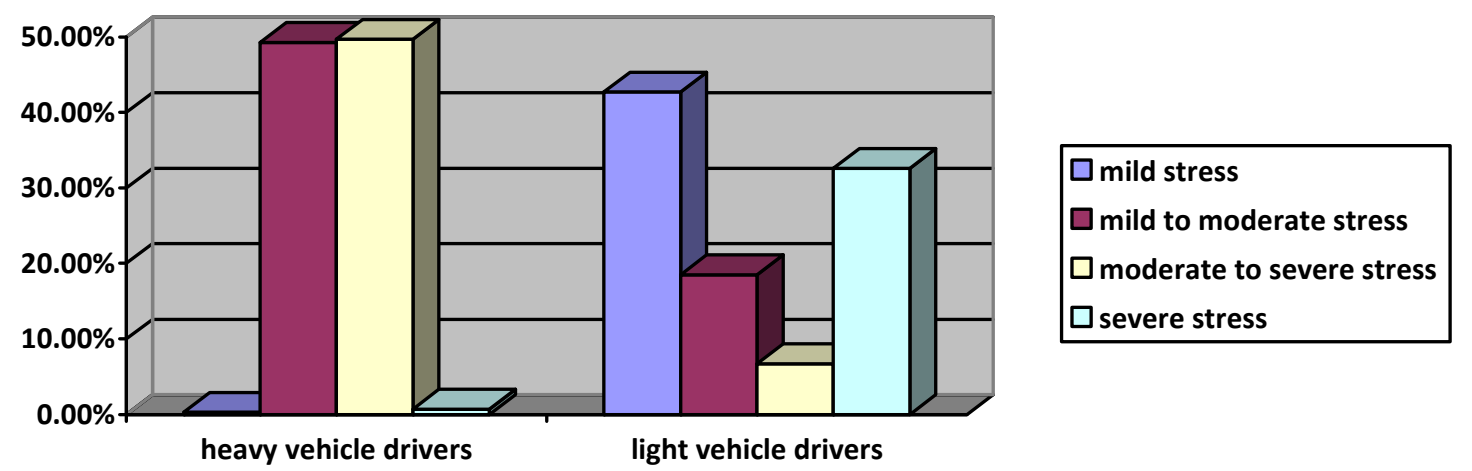

Figure 1. Job stress level in heavy and light vehicle drivers

Linear regression model was used to eliminate the effects of confounding variables on stress. Variables such as age, income, educational level, type of vehicle (heavy and light), rest duration, shift work, and job satisfaction were entered in the model. Based on the analysis ( $\mathrm{R}$ square $=0.11, \mathrm{p} \leq 0.001)$, independent stress predictors were as follows: vehicle type, shift work, job satisfaction, and income level. light vehicle driving reduced stress by 33 units compared to heavy vehicle driving ( $\mathrm{p} \leq 0.001$, CI 95\%:19-41); income level of over 188 dollars increased stress by 33 units ( $\mathrm{p} \leq 0.001$, CI 95\%:18-49), job dissatisfaction increased stress by 20 units ( $\mathrm{p} \leq 0.001$, CI 95\%:11-28) and shift work and varied working shift pattern reduced stress 25 units compared to day-working $(\mathrm{p} \leq 0.001, \mathrm{CI}=15-35)$.

Given the low number of night-shift drivers $(n=23)$ than day-shift drivers and those with varied working shift pattern, regression analysis was performed to compare day-working with varied working shift pattern. Based on the analysis, working in varied shifts decreases stress score by 25 units.

Table 1. Logistic regression model controlled for type of vehicle (heavy and light), age, education, income, varied shift, rest duration and job satisfaction

\begin{tabular}{lllll}
\hline Variable & Standard Error & Beta & P-value & CI \\
\hline Vehicle type & 5.64 & -0.29 & $\leq 0.001$ & -41.50 to -19.32 \\
Age & 0.38 & -0.02 & 0.63 & -0.94 to 0.57 \\
Education & 4.81 & 0.02 & 0.61 & -7.03 to 11.88 \\
Income level & 8.03 & 0.17 & $\leq 0.001$ & 18.07 to 49.62 \\
Varied shift & 5.18 & -0.25 & $\leq 0.001$ & -35.81 to -15.46 \\
Rest duration & 4.61 & 0.06 & 0.12 & -1.94 to 16.19 \\
Job satisfaction & 4.43 & 0.17 & $\leq 0.001$ & 11.39 to 28.83 \\
\hline
\end{tabular}


In assessment of stress categories in all drivers, the highest score was attributed to role insufficiency (29.86 \pm 9.29$)$. In comparison between two groups of drivers, the mean stress scores were significantly higher in work load, role conflict, responsibility, and physical work environment as well as overall stress level in heavy vehicle drivers than light vehicle drivers $(\mathrm{p}<0.001)$, while this difference was not statistically significant in terms of role insufficiency and ambiguity.

According to the analysis of variance (ANOVA), there was a significant difference between total stress score in light vehicle drivers in terms of type of task (taxi, agency, school service and company drivers) $(p<0.001)$. After performing Dunnett T3 test in Post hoc test, we found that taxi drivers had significantly higher stress than other light vehicle drivers $(\mathrm{p}<0.001, \mathrm{p}<0.002$, and $\mathrm{p}=0.006$, respectively). Post hoc test also indicated that agency drivers significantly had less stress than taxi and company drivers $(\mathrm{p}<0.001)$. Total stress score and its domains in light vehicle drivers are presented in Table 2.

Table 2. Comparison of stress score and its domains in light vehicle drivers*

\begin{tabular}{llllllr}
\hline Type of task & $\begin{array}{l}\text { Total Stress } \\
\text { Score }\end{array}$ & Workload & $\begin{array}{l}\text { Role } \\
\text { Ambiguity }\end{array}$ & $\begin{array}{l}\text { Role } \\
\text { Insufficiency }\end{array}$ & $\begin{array}{l}\text { Role } \\
\text { Conflict }\end{array}$ & $\begin{array}{l}\text { Physical } \\
\text { Responsibility } \\
\text { Environment }\end{array}$ \\
\hline $\begin{array}{l}\text { Taxi Driver } \\
\text { Agency }\end{array}$ & $203.42 \pm 67.65$ & $23.17 \pm 12.17$ & $35.18 \pm 11.98$ & $35.12 \pm 12.5$ & $31.83 \pm 7.24$ & $36.39 \pm 13.7$ \\
$\begin{array}{l}\text { Driver } \\
\text { School }\end{array}$ & $130.63 \pm 38.42$ & $19.48 \pm 7.34$ & $24.35 \pm 6.75$ & $23.68 \pm 6.75$ & $24.64 \pm 4.87$ & $20.13 \pm 8.09$ \\
$\begin{array}{l}\text { Driver } \\
\text { Company }\end{array}$ & $152.78 \pm 64.32$ & $24.21 \pm 11.99$ & $28.43 \pm 11.72$ & $27.43 \pm 11.63$ & $27.71 \pm 6.54$ & $22.93 \pm 12.74$ \\
$\begin{array}{l}\text { Driver } \\
\text { P- value }\end{array}$ & $172.36 \pm 64.20$ & $28.19 \pm 12.35$ & $30.77 \pm 10.11$ & $31.16 \pm 11.95$ & $28.93 \pm 6.87$ & $28.66 \pm 13.76$ \\
\hline
\end{tabular}

$*$ mean $\pm \mathrm{SD}$

According to compared mean score of total stress in heavy vehicle drivers in terms of type of task (bus, chemical tanker, trailer, truck, and other heavy vehicles drivers), the ANOVA indicated that there were significant differences between these subgroups $(\mathrm{p}<0.001)$. According to Dunnett T3 in Post hoc test, we found that the chemical tanker drivers (fuel, solvents, pesticides, etc) and bus drivers had significant higher stress than others $(\mathrm{p}<0.001)$. Total stress score and its domains in heavy vehicle drivers are presented in Table 3.

Table 3. Comparison of stress score and its domains in heavy vehicle drivers*

\begin{tabular}{llllllll}
\hline Type of task & $\begin{array}{l}\text { Total Stress } \\
\text { Score }\end{array}$ & Workload & $\begin{array}{l}\text { Role } \\
\text { Ambiguity }\end{array}$ & $\begin{array}{l}\text { Role } \\
\text { Insufficiency }\end{array}$ & $\begin{array}{l}\text { Role } \\
\text { Conflict }\end{array}$ & Responsibility & $\begin{array}{l}\text { Physical } \\
\text { Environment }\end{array}$ \\
\hline $\begin{array}{l}\text { Chemical } \\
\text { tanker driver }\end{array}$ & $216.45 \pm 22.4$ & $37.56 \pm 2.69$ & $32.79 \pm 3.86$ & $35.56 \pm 3.39$ & $36 \pm 3.34$ & $36.49 \pm 3.69$ & $41.46 \pm 2.34$ \\
$\begin{array}{l}\text { Bus driver } \\
\text { Tanker \& }\end{array}$ & $221.4 \pm 10.08$ & $40.82 \pm 2.02$ & $33.44 \pm 5.15$ & $35.71 \pm 3.91$ & $35.37 \pm 3.89$ & $42.8 \pm 3.53$ & $33.24 \pm 2.40$ \\
trailer driver & $157.11 \pm 21.54$ & $29.71 \pm 5.9$ & $27.22 \pm 4.36$ & $27.88 \pm 4.39$ & $28.86 \pm 4.26$ & $28.87 \pm 5.85$ & $32.50 \pm 2.53$ \\
others & $166.35 \pm 10.97$ & $27.66 \pm 6.73$ & $26.33 \pm 2.71$ & $26.46 \pm 3.24$ & $28.4 \pm 4.46$ & $25.66 \pm 2.19$ & $31.66 \pm 1.83$ \\
P- value & $\leq 0.001$ & $\leq 0.001$ & $\leq 0.001$ & $\leq 0.001$ & $\leq 0.001$ & $\leq 0.001$ & $\leq 0.001$ \\
\hline
\end{tabular}

$*$ mean \pm SD

\section{Discussion}

According to the results of this study, the total stress was moderate to severe in heavy- vehicle drivers, while it was mild to moderate in light vehicle drivers. This case is justifiable since job stressors are clearly higher in heavy vehicle drivers than the light vehicles. Higher responsibility for individual's life and capital in heavy-vehicle drivers is amongst these stressors.

$44.3 \%$ of the whole participants had moderate to severe stress level. However, in a research by Aminian et al, $78 \%$ of public transport drivers had moderate to severe stress perhaps due to the differences in the studied population. (Aminian, Farjami, Pouryaghoob, \& Sadeghniiat, 2011) 
In terms of different domains of stress in all drivers, the highest score belonged to the role insufficiency. According to the definition of role insufficiency, individuals believe that their training, qualifications and experience do not fit their job requirements (Jackson, 2004). In fact, professional drivers are expected to show faster reaction time, regularly control their vehicles and carry out routine maintenance, and have minimum mental competence. For instance, they should remain calm in critical conditions and avoid aggressive behavior, but in Iran professional drivers are deprived such specialized training both before and during their career and they can only get benefit from their pioneers' experience.

In the present study, the mean score of total stress was significantly higher in chemical tanker (fuels, solvents, pesticides, etc) and bus drivers than truck and trailer drivers and the others (e.g light truck, dump truck, etc.) perhaps due to the importance of type of cargos.

Heavy vehicle drivers had higher stress scores in work load, role conflict, responsibility and physical work environment than light vehicle drivers; and the highest scores in role conflict and work environment belonged to chemical tanker drivers. Stressors of work environment include physical hazards (noise, heat, cold, and vibration), ergonomic problems, unpleasant odors and safety hazards. Certainly, the first two stressors are common in heavy-vehicle drivers, but safety hazards and unpleasant odors are considered more serious problems in chemical tanker drivers. According to a research by Krishnan et al on gas and oil tanker drivers, there was significant relationship between psychological factors including job stress and fatigue, which this might result in reducing drivers' efficiency and increasing traffic accidents. (Krishnan, Hizam, Firdhaus, Sarah, \& Taufiq, 2017)

According to the previous studies, role conflict occurs when a person is in contradictory situations. Furthermore, it may come about when a person is dissatisfied with existing job expectations (Yongkang, Weixi, Yalin, Yipeng, \& Liu, 2014). Those experiencing role conflict may gradually begin to believe that they are unable to successfully carry out their job tasks and expectations (Piko, 2006). Therefore, there is a need to pay special attention to the importance of adverse consequences of this issue especially in heavy vehicle drivers.

According to the analysis, the highest scores of work load, role insufficiency, role ambiguity and responsibility in heavy-vehicle drivers belonged to bus drivers. In other words, bus drivers believed that there was not any consistency between quantity and quality of expected occupational activities with their abilities and required time to do their job roles. Numerous studies have been conducted on job stress in bus drivers (Bergomi, Modenese, Ferretti, Ferrari, Licitra, Vivoli, Gobba, \& Aggazzotti, 2017; Bathija, Bant, Itagimath, Lokare, Godbole, Nekar, Mahesh, \& Kantesh Reddi, 2014; Roohi \& Hayee, 2010; Du, Lin, Lu, \& Tai, 2011; Yamada, Mizuno, Sugiura, Tanaka, Mizuno, Yanagiya, \& Hirosawa, 2008; Kompier, Aust, Van den Berg, \& Siegrist, 2000), despite the fact that these studies have not paid much attention to various subgroups and domains of job stress. According to all of these studies, bus driving is among the jobs with low control and high demand and includes significant psychological expectations due to the following reasons. A bus driver should be adapted to conflicting demands and expectations. Employer companies and people expect drivers to establish good relationships with passengers and provide good service. For instance, bus drivers are expected to provide necessary and sufficient information about departure time, routes and bus stop time for passengers and stop at certain intervals, but fulfillment of such expectations is often in conflict with obligations to keep an accurate schedule in heavy traffic. Driving should be also in accordance with driving rules and regulations. In addition, this group of professional drivers is faced with threats and violence by troublesome passengers. Bus drivers are often forced to work in varied shifts, and thus they have irregular rest days which do not match with family members' programs. Since bus drivers are responsible for passengers' safety and health, higher stress in this group of drivers is inevitable. In a research by Golmohammadi et al., $76 \%$ of bus drivers complained of high stress. Quality of individual relationship with supervisors and colleagues, amount of individual interest in his job and the work environment were among important stress-related factors in that study (Golmohamadi, Damyar, Mohamadfam, \& Faradmal, 2013). In another research, one third of bus drivers suffered from intense stress. Based on results of this study, there was a significant relationship between stress with older age and varied shift work pattern (Varmazyar, Mortazavi, Hajizadeh, \& Arghami, 2013). These results were consistent with the results of the present study.

According to the analysis on light vehicle drivers, total stress score was significantly higher in taxi drivers than others (agency, school service, and company drivers). Moreover, taxi drivers had the highest stress score in all stress domains. Conversely, the minimum stress domains scores were belonged to agency drivers. What has been observed in taxi drivers was probably due to the competition with other coworkers for picking up the passengers, dealing with different social classes during a working day, further use of the vehicle and thus higher depreciation and its imposed excess costs on taxi owners, longer exposure to urban traffic, and lack of specific working schedule and determined monthly income in taxi drivers. (B. Choi, S. Choi, Jeong, Lee, Shu, Yu, Ko, \& Zhu, 
2016; Wang \& Delp, 2014; Apantaku-Onayemi, Baldyga, Amuwo, Adefuye, Mason, Mitchell, \& Blumenthal, 2012; Chen, Chang, Chang, \& Christiani, 2005; Hattori \& Azami, 2001; Nakano et al., 1998)

The relatively high sample size and including different groups of professional light and heavy-vehicle drivers were among the strengths of the present study. Furthermore, a few studies have investigated different domains of stress in professional drivers so far.

This study was a cross-sectional study; thus, existence of a causal relationship could not be verified, though this is an inevitable issue in cross-sectional studies. Self-reported questionnaires might have led to bias in responses; however, there has not been any reliable objective method in this regard so far. It should be noted that our study was only conducted on professional male drivers. Since the majority of drivers in Iran are male, the studied sample probably represents the Iranian professional drivers' society.

\section{Conclusion}

According to the results of this study, nearly half of the participants had moderate to severe stress; and overall stress level was higher in heavy vehicle drivers than light vehicle drivers. In heavy vehicle drivers, the highest level of stress belonged to chemical tanker and bus drivers. Taxi drivers received the highest scores of stress among light vehicle drivers. Among various domains of stress in all drivers, the highest score belonged to the role insufficiency. Heavy vehicle drivers also received higher scores in work load, role conflict, responsibility, and physical work environment than light vehicle drivers.

According to previous studies and the present research, despite the proven adverse effects of psychological problems on drivers' performance and safety, this issue is still neglected in professional drivers, and unfortunately there is not enough attention to the origins of job stress and its management -especially in heavy vehicle drivers- in Iran. Therefore, health planners should pay greater attention to this issue and put tanker, bus and taxi drivers in the first priority for job stress management programs due to their higher stress levels in the case of limited resources.

\section{Conflict of interests}

The authors declare that there is no conflict of interests regarding the publication of this paper.

\section{References}

Aminian, O. (2005). Stress on drivers. Tehran; Driver's Occupational Health Seminar.

Aminian, O., Farjami, A., Pouryaghoob, G., \& Sadeghniiat, H. K. (2011). The evaluation of effect of job stress on the risk factors of the cardiovascular diseases among the drivers in Tehran in 86. tkj., 2(1), 26-33.

Apantaku-Onayemi, F., Baldyga, W., Amuwo, S., Adefuye, A., Mason, T., Mitchell, R., \& Blumenthal, D. S. (2012). Driving to better health: Cancer and cardiovascular risk assessment among taxi cab operators in Chicago. J Health Care Poor Underserved, 23(2), 768-80.

Bathija, G., Bant, D., Itagimath, S., Lokare, L., Godbole, M., Nekar, M., Mahesh, K., \& Kantesh Reddi, K. A. (2014). Study on stress among government city bus drivers in Hubli. IJBR, 5(2), 102-104.

Bergomi, M., Modenese, A., Ferretti, E., Ferrari, A., Licitra, G., Vivoli, R., Gobba, F., \& Aggazzotti, G. (2017). Work-related stress and role of personality in a sample of Italian bus drivers. Work, 57(3), 433-440.

Chen, J. C., Chang, W. R., Chang, W., \& Christiani, D. (2005). Occupational factors associated with low back pain in urban taxi drivers. Occup Med (Lond)., 55(7), 535-40. Epub 2005 Sep 1.

Choi, B., Choi, S., Jeong, J., Lee, J., Shu, S., Yu, N., Ko, S., \& Zhu, Y. (2016). Ambulatory heart rate of professional taxi drivers while driving without their typical psychosocial work stressors: A pilot study. Ann Occup Environ Med., 28, 54. eCollection 2016.

KIZILOĞLU, M. (2018). A RESEARCH ON THE RELATIONSHIP BETWEEN WORKPLACE MONITORING AND JOB STRESS. Journal Of Organizational Behavior Research, 3 (2), 1-12.

Du, C. L., Lin, M. C., Lu, L., \& Tai, J. J. (2011). Correlation of Occupational Stress Index with 24-hour Urine Cortisol and Serum DHEA Sulfate among City Bus Drivers: A Cross-sectional Study. Saf Health Work, 2(2), 169-75.

Golmohamadi, R., Damyar, N., Mohamadfam, I., \& Faradmal, J. (2013). Study of Occupational Stress Among Hamadan City-Bus Drivers, 2011. TB., 12(1), 24-32. [Persian] 
Hattori, M., \& Azami, Y. (2001). Searching for preventive measures of cardiovascular events in aged Japanese taxi drivers--the daily rhythm of cardiovascular risk factors during a night duty day. J Hum Ergol (Tokyo), $30(1-2), 321-6$.

Hoel, H., Sparks, K., \& Cooper, C. L. (n. d.). The cost of violence/Stress at work and the benefits of a violence/stress-free working environment. Retrieved from http://www.ilo.org/public/english/protection/ safework/whpwb/econo/costs

Jackson, A. (2004). A Survey of the Occupational Stress, Psychological Strain, and Coping Resources of Licensed Professional Counselors in Virginia: A Replication Study. Retrieved from http://hdl.handle.net/10919/30206.thesis.degree.namePhD.dc.identifier.sourceurl; http://scholar.lib.vt.edu/theses/available/etd-12212004-144456/

Kompier, M. A., Aust, B., Van den Berg, A. M., \& Siegrist, J. (2000). Stress prevention in bus drivers: Evaluation of 13 natural experiments. J Occup Health Psychol, 5(1), 11-31.

Krishnan, S., Hizam, S., Firdhaus, A., Sarah, S., \& Taufiq, A. (2017). Analysis of Exhaustion Related Psychological Risk Factors among Oil and Gas Tanker Drivers in Malaysia. International Journal of Advanced and Multidisciplinary Social Science, 3(1), 22-27.

LaDou, J., \& Harrison, R. (2007). Current occupational \& environmental medicine. New York: McGraw-Hill. Retrieved from http://www.careercast.com/jobs-rated/most-stressful-jobs-2014.

Haider, S. H., Nisar, Q, Al., Baig, F., Azeem, M., Hameed, W. (2018). Dark Side of Leadership: Employees’ Job Stress \& Deviant Behaviors in Pharmaceutical Industry. International Journal of Pharmaceutical Research \& Allied Sciences, 2018, 7(2), 125-138.

LaDou, J., \& Harrison, R. (2014). Current occupational \& environmental medicine. New York: McGraw-Hill.

Nakano, Y., Nakamura, S., Hirata, M., Harada, K., Ando, K., Tabuchi, T., Matunaga, I., \& Oda, H. (1998). Immune function and lifestyle of taxi drivers in Japan. Ind Health, 36(1), 32-9.

Osipow, S. H., \& Spokan, A. R. (1998). Manual for occupational stress inventory: Research version. Psychological Assessment Resources, Odessa, FL, USA.

Piko, B. (2006). Role Conflict and Burnout: The Direct and Moderating Effects of Political Skill and Perceived Organizational Support on Burnout Dimensions. Int J Nurs Stud., 43(3), 311-8.

Roohi, N., \& Hayee, S. (2010). Work stress related physiological responses in professional bus drivers. Acta Physiol Hung, 97(4), 408-16.

Sharifian, S. A., Aminian, O., Kiani, M., Baruni, Sh., \& Amiri, F. (2005). The evaluation of the degree of occupational stress and factors influencing it in forensic doctors working in legal medicine organization in Tehran. J. Forens. Med., 12(3), 144-150. [Persian].

Siedlecka, J. (2006). Selected work-related health problems in drivers of public transport vehicles. Med Pr., $57(1), 47-52$.

Tangri, R. P. (2003). What stress costs: A special report. Canada: Performance Strategies Publication. Retrieved from http://www.stresscost.com

Varmazyar, S., Mortazavi, B., Hajizadeh, I., \& Arghami, S. (2013). Evaluation of the Status of Severe Occupational Stress and Its Associated Factors among Public Transportation Bus Drivers in Tehran, 2012, Iran. Qom Univ Med Sci J, 7(5), 73-82.

Varmazyar, S., Mortazavi, B., Hajizadeh, I., \& Arghami, Sh. (2013). Evaluation of the status of severe occupational stress and its associated factors among public transportation bus drivers in Tehran, 2012, Iran. Qom Univ Med Sci J, 7(5), 73-82. [Full Text in Persian]

Vrijkotte, T. G., Van Doornen, L. J., \& De Geus, E. J. (1999). Work stress and metabolic and hemostatic risk factors. Psychosomatic Medicine, 61(6), 796.

Hannani, S., Rezagholy, P., Nasiri Ziba, F., Ali Azadi, N. (2018). Relationship Between Sleep Quality with Job Stress and Quality of Life of Operating Room Technologists Working in University Hospitals Affiliated to Iran University of Medical Sciences in 2016-17. Pharmacophore, 9(2), 103-108.

Wang, P. C., \& Delp, L. (2014). Health status, job stress and work-related injury among Los Angeles taxi drivers. Work, 49(4), 705-12. 
Yamada, Y., Mizuno, M., Sugiura, M., Tanaka, S., Mizuno, Y., Yanagiya, T., \& Hirosawa, M. (2008). Bus drivers' mental conditions and their relation to bus passengers' accidents with a focus on the psychological stress concept. J Hum Ergol (Tokyo), 37(1), 1-11.

Yongkang, Z., Weixi, Z., Yalin, H., Yipeng, X., \& Liu, T. (2014). The Relationship among Role Conflict, Role Ambiguity, Role Overload and Job Stress of Chinese Middle-Level Cadre. ChnStd., 3(1), 8-11. Retrieved from http://www.scirp.org/journal/chnstd

\section{Copyrights}

Copyright for this article is retained by the author(s), with first publication rights granted to the journal.

This is an open-access article distributed under the terms and conditions of the Creative Commons Attribution license (http://creativecommons.org/licenses/by/4.0/). 